\title{
Bacterium-like particles for efficient immune stimulation of existing vaccines and new subunit vaccines in mucosal applications
}

\author{
Natalija Van Braeckel-Budimir ${ }^{\dagger}$, Bert Jan Haijema ${ }^{\dagger}$ and Kees Leenhouts*
}

Mucosis BV, Groningen, Netherlands

\section{Edited by:}

Val Ferro, University of Strathclyde,

UK

\section{*Correspondence:}

Kees Leenhouts, Mucosis B.V., L.J. Zielstraweg 1, 9713 GX Groningen, Netherlands

e-mail: leenhouts@mucosis.com

${ }^{\dagger}$ Natalija Van Braeckel-Budimir and Bert Jan Haijema have contributed equally to this work.
The successful development of a mucosal vaccine depends critically on the use of a safe and effective immunostimulant and/or carrier system. This review describes the effectiveness and mode of action of an immunostimulating particle, derived from bacteria, used in mucosal subunit vaccines. The non-living particles, designated bacterium-like particles are based on the food-grade bacterium Lactococcus lactis. The focus of the overview is on the development of intranasal BLP-based vaccines to prevent diseases caused by influenza and respiratory syncytial virus, and includes a selection of Phase I clinical data for the intranasal FluGEM vaccine.

Keywords: carrier-adjuvant, mucosal vaccine technology, particles, Lactococcus lactis, influenza vaccines, RSV vaccines

\section{INTRODUCTION}

A key issue in the development of improved and new vaccines is safety, since most vaccines are given to healthy individuals. In order to improve safety profiles, the use of well-defined (recombinant) purified antigens for the generation of subunit vaccines has become key in vaccine development programs. In addition, there is an increasing interest to explore other modes of vaccine administration besides the use of needles. Since purified soluble antigens are usually poorly immunogenic, even more so when delivered through mucosal (nasal, oral) routes, the addition of safe immunostimulators/adjuvants to increase the efficacy of vaccines is needed (1-3).

In order to minimize regulatory hurdles, we have developed a non-living particle that can be used as an immunostimulant for the improvement of existing vaccines and to enable mucosal application, or can be used additionally as a vaccine carrier for subunit antigens. The particles are based on non-recombinant Lactococcus lactis bacteria. L. lactis is an innocuous Gram-positive bacterium that is commonly used in the food industry; it has Generally Recognized As Safe (GRAS) status of the Food and Drug Administration (FDA). The safe background of $L$. lactis makes it highly suitable for use in vaccines. The Gram-positive bacterial cell surface consists of a single membrane on the inside and a thick cell-wall on the outside $(4,5)$. The cell-wall is built up of multiple layers of peptidoglycan (PGN) with various other components that may protrude both on the inside and outside. A simple pretreatment in hot acid destroys all cellular components, including intracellular components such as DNA. Cell-wall components other than the rigid PGN matrix are also degraded. The result is a non-living particle that retains the same shape and size as the bacterium before treatment. Acid treatment is followed by extensive washing with buffer to remove acid and degradation products (6). The procedure results in nonliving spherical shaped bacterium-like particles (BLPs) that have a diameter of approximately $1-2 \mu \mathrm{m}$ and consist predominantly of a PGN outer surface (Figure 1).

As previously mentioned, BLPs are used in two different formats. They are used as an immunostimulant by simply mixing with vaccine antigens (admixed). This format is of particular interest in the reformulation of existing vaccines to enable mucosal application. The preferred format for use in recombinant subunit vaccines is a formulation in which the antigens are bound to the surface of BLPs. Binding of antigens to BLPs requires the presence of a PGN binding tag (Protan) in the antigen. The PGN binding domain of the L. lactis AcmA cell-wall hydrolase (7) has been used for this purpose (8). Antigen-Protan fusions have been produced in prokaryotic (L. lactis, E. coli) and eukaryotic hosts (insect, $\mathrm{CHO}$, and HEK cells). To date, over 40 different antigens of bacterial, viral, or parasitic nature have been successfully overexpressed as Protan fusions using these expression hosts (9). The Protan fusions are secreted preferably by the expression cells, allowing easy removal of the production cells. Conventional protein isolation techniques are then used to purify the Protan fusion product. The purified fusion is subsequently mixed with BLPs to allow binding. The BLPs with bound antigen-Protan fusion are subsequently recovered, washed, and formulated in a suitable buffer (Figure 1).

A more extensive overview of BLP and Protan characteristics was recently published elsewhere (9).

\section{IMMUNOGENICITY OF BLP-BASED VACCINES: IN VIVO STUDIES}

Although the focus of this paper is on the mucosal use of BLPbased vaccines, Table 1 provides an overview of all mucosal and parenteral BLP-based vaccines tested to date as a proof-of-concept for immunogenicity and protection against pathogenic challenge. The immunogenicity and protection capacity of both BLP-based 


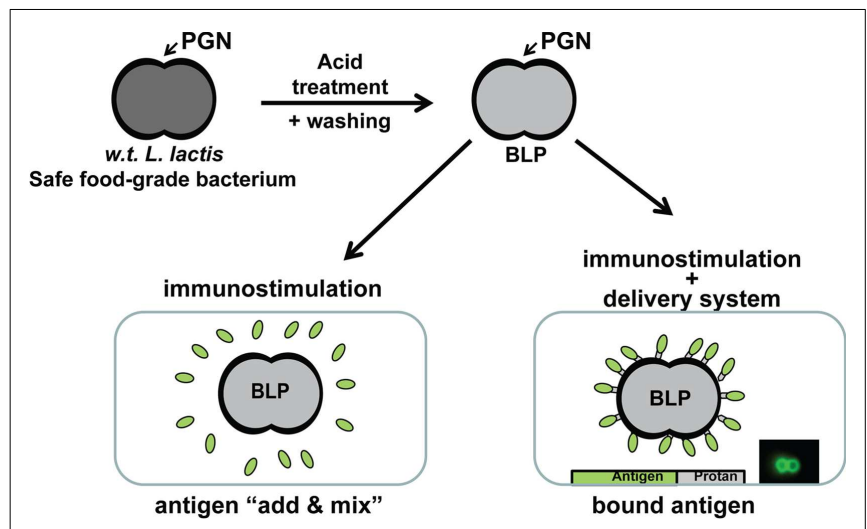

FIGURE 1 | Overview of the production and use of BLPs. After treatment in hot acid, degradation products and acid are removed by washing with phosphate buffered saline (PBS). The BLPs are finally formulated in PBS. Vaccines are made by BLPS admixed with antigens (this formulation is of particular interest for the reformulation of existing vaccines) or antigens are bound to the surface of the BLPs. For this latter format, it is a requirement that the subunit antigens are produced as a fusion protein with the Protan tag in a suitable production organism. Mixing of an antigen-Protan solution with BLPs results in instant, strong, and stable non-covalent binding such that BLPs are completely covered at the surface with the antigen.

admixed vaccines and vaccines in which the antigen was bound to the BLPs has been tested extensively in various animal models. The listed studies demonstrate robust antigen-specific systemic immune responses after parenteral vaccination and both strong local and systemic responses induced upon mucosal vaccination. Furthermore, the induced immune responses have proven to be protective against infections with specific pathogens, including viruses, bacteria, and parasites.

\section{MUCOSAL ADMINISTRATION OF BLP-BASED VACCINES AGAINST RESPIRATORY VIRUSES}

Most intensively studied and advanced BLP-based vaccines are formulations against respiratory viruses including: seasonal influenza vaccine (FluGEM) and Respiratory Syncytial Virus (RSV) vaccine (SynGEM). In the following section we provide an overview of the results of immunization and protection studies performed in influenza- and RSV-animal models.

\section{FluGEM in animal models}

Influenza is an acute respiratory illness that mostly affects the upper, and sometimes also the lower, respiratory tract and is caused by the influenza virus. It represents an important, often underestimated public health problem and is associated with increased general practice consultation rate, hospital admissions and excess deaths (17). In addition, influenza has a high impact on health care planning, and is also one of the major causes of increased absenteeism from work and school, and thus has significant economic impact. Every year approximately $5-10 \%$ of the global population is infected with influenza, while during a major epidemic the attack rate might increase up to $50 \%$. The World Health Organization (WHO) has estimated that 3-5 million of annually infected people develop a severe form of the disease and of those, 250,000-500,000 die (18).
Influenza virus is a negative-sense ssRNA virus and it belongs to the family of Orthomyxoviridae (19). The virion is composed of an external envelope derived from plasma membrane of the infected cell that contains viral surface glycoproteins. Additionally, the viral particle contains an internal core, composed of the viral genome associated with specific proteins (20). The surface of the viral particle is covered by numerous protein spike-like projections. These are molecules of hemagglutinin (HA) and neuraminidase (NA); two major surface glycoproteins (20). Besides HA and NA, the viral envelope also contains membrane protein 2 (M2) (20). In addition to the envelope glycoproteins, the genome of influenza virus also encodes the matrix protein (M1), viral polymerase proteins, the nucleoprotein (NP), and a number of non-structural proteins (20).

Vaccination is the most effective method of preventing influenza virus infection and its potentially severe complications. Current influenza vaccination strategies are mostly based on inactivated virus vaccines (subunit, split-virion, virosome, whole inactivated virus), which are generally administered through intramuscular injection and induce antibodies against $\mathrm{HA}$ - one of the two surface viral glycoproteins and the main antigenic component of the virus (21). Parenterally administered vaccines usually induce potent systemic responses, but no local, mucosal response at the port of viral entry. This lack of induced mucosal response might be a limitation of the protective capacity of such vaccines (22).

Our goal is the development of a mucosal, more specifically, an intranasal influenza vaccine. In contrast to parenteral vaccination, this route of vaccine administration would activate local mucosal responses at the port of viral entry, e.g., secretory IgA (S-IgA), in addition to systemic responses. Therefore, an intranasal vaccine may provide a powerful first line of defense against influenza. This would lead to reduction of virus entry, but also to reduction in virus replication and shedding. Furthermore, intranasal vaccination does not require trained health care personnel for the administration of the vaccine and does not bear the risk of needle stick injuries (23).

In order to achieve maximum immunogenicity when introduced through the i.n. route, inactivated influenza vaccines require the presence of immunostimulating compounds. Several adjuvants have been extensively evaluated as potential candidates for mucosal vaccination, such as nucleic acids and bacterial components (e.g., toxins) (24, 25). Despite good immunogenicity profiles, development of many of the aforementioned adjuvants is hampered by safety and regulatory concerns (26). Therefore, a safe adjuvant/immunostimulant, suitable for i.n. influenza vaccination, with a good immunopotentiating capacity is still highly desirable.

We have developed two types of intranasal influenza vaccines. The first type, FluGEM-A (A stands for admixing), is based on a mixture of BLPs with commercially available influenza vaccine antigen (subunit or split-virion vaccine). The second type, FluGEM-B (B stands for bound), contains purified influenza HA and/or M2 protein ectodomain (M2e) bound to BLPs, as described in the Section "Introduction." Both vaccines have been extensively tested for safety and immunogenicity in animals, and FluGEM-A has also been tested in a Phase I clinical trial (see Final Remarks of this review). 
Table 1 | Overview of preclinical proof-of-concept studies performed using different BLP-based vaccine formulations.

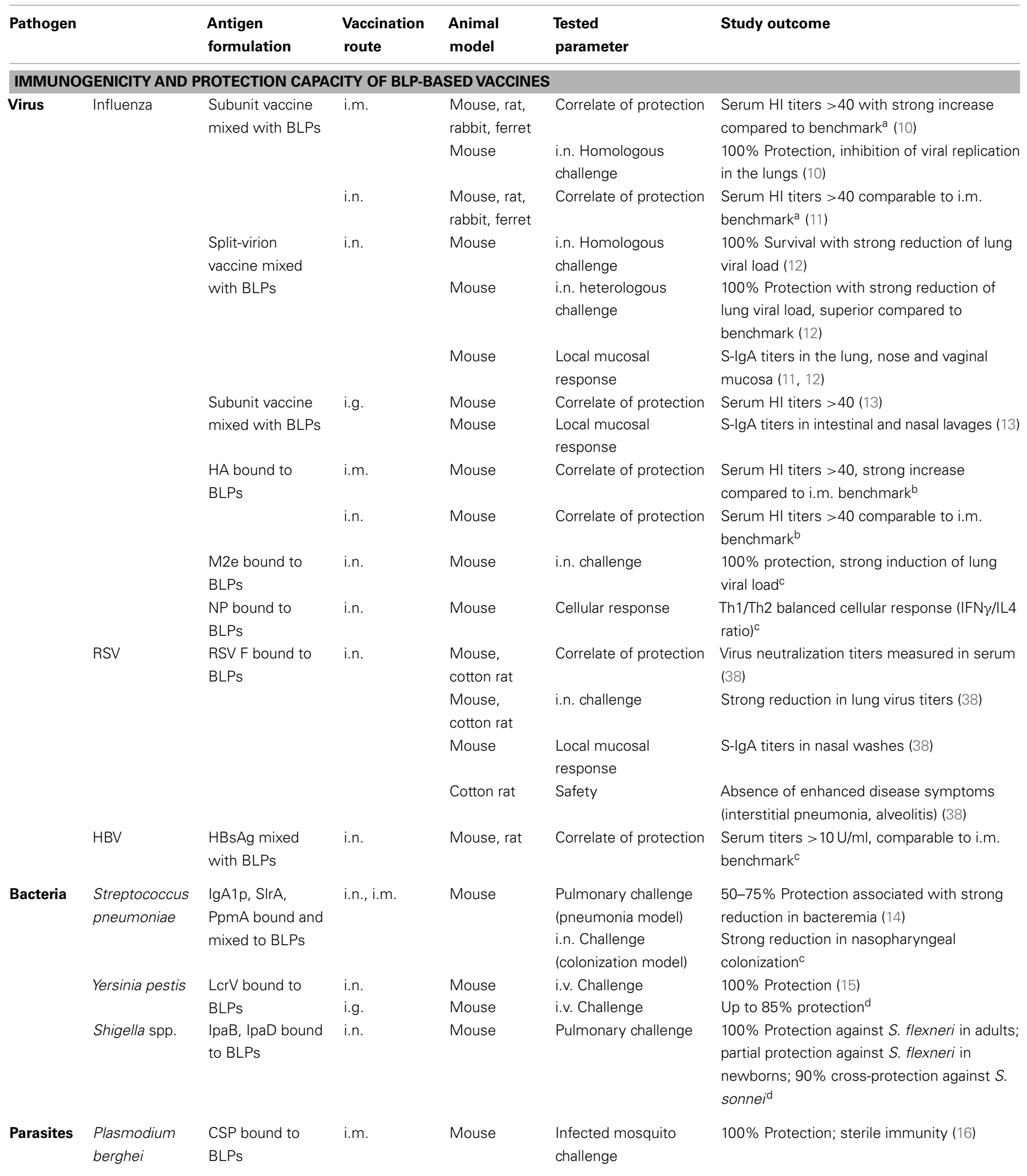

RSV, respiratory syncytial virus; HBV, hepatitis B virus; i.m., intramuscular; i.n., intranasal; i.g., intragastric; i.v., intravenous; HI, hemagglutination inhibition; S-IgA, secretory IgA; HA, hemagglutinin; M2e, M2 ectodomain; NP, nucleoprotein; F, fusion protein; HBsAg, HBV surface antigen; IgA1p, immunoglobulin A1 protease; SIrA, streptococcal lipoprotein rotamase A; PpmA, proteinase maturation protein A; LcrV, low-calcium response virulence antigen; Ipa, invasion plasmid antigen; CSP, circumsporozoite protein; ${ }^{a}$ seasonal i.m. non-adjuvanted influenza subunit or split-virion vaccine; ${ }^{b}$ manuscripts in preparation; ${ }^{c}$ mucosis, unpublished data; ${ }^{d} P a s e t t i$, unpublished data. 
Influenza antigen admixed with BLPs: FluGEM-A. To evaluate the immunogenicity of FluGEM-A, mice were vaccinated i.n. with FluGEM-A formulation, composed of seasonal subunit vaccine mixed with BLPs. Control groups were i.m. (benchmark) or i.n. vaccinated with a non-adjuvanted equivalent.

Immunogenicity of FluGEM-A vaccine. Intranasal vaccination of mice with FluGEM-A induced serum hemagglutination inhibition (HI) titers well above the determined protective titer of 40, which was comparable with HI titers measured in the sera of animals vaccinated i.m. with seasonal subunit (benchmark) vaccine, and significantly higher than titers induced by i.n. vaccination with unadjuvanted subunit vaccine (11) (Figure 2A). Similarly, influenza HA-specific IgG titers comparable to those induced upon i.m. benchmark vaccination were measured in sera of mice i.n. vaccinated with FluGEM-A (11). Importantly, subtyping of influenza HA-specific IgG antibodies revealed that i.n. vaccination with FluGEM-A induced well-balanced responses, with an IgG2a/IgG1 ratio of 0.9. Cytokine profiles assessed in spleens of vaccinated animals were characterized by higher production of Th1-polarized cytokines (IFN- $\gamma$ and IL-2) and lower production of IL-4, a Th2-polarized cytokine, when compared to cytokines induced upon benchmark vaccination (11). Finally, i.n. immunization with FluGEM-A, in contrast to benchmark vaccination, induced strong local S-IgA responses, especially important as the first line of defense at the port of virus entry $(11,12)$ (Figure 2B).

In addition to strong systemic and mucosal responses, i.n. vaccination with FluGEM-A induced immune responses that seem to wane slower than the response induced upon i.m. vaccination with a non-adjuvanted benchmark vaccine. As depicted in Figure 2C, serum IgG titers induced by i.n. vaccination with FluGEMA remained stable throughout the follow-up period of almost 4 months after the final immunization and were still boostable. This observation is suggestive of induction of influenza-specific memory B-cells and the presence of long-lived antibody secreting plasma cells. On the other hand, IgG titers induced by i.m. benchmark vaccination after 4 months decreased to approximately a quarter of the initial post-vaccination value.
Similar immunogenicity profiles and immunopotentiating capacities of BLPs were demonstrated for FluGEM-A in other animal models such as rats, rabbits, and ferrets (9).

Protection against homologous and heterologous challenge induced by intranasal vaccination with FluGEM-A. The protection capacity of i.n. administered FluGEM-A vaccines was assessed in homologous challenge studies using an influenza PR8 challenge model. To this end, mice were two or three times i.n. vaccinated with FluGEM-A containing a PR8-derived splitvirion vaccine (12). Control mice were vaccinated i.m. or i.n. with non-adjuvanted split-virion vaccine. Results of the study clearly demonstrated that vaccination with two or three doses of FluGEM-A vaccine confers solid protection against infection with a homologous virus strain. The degree of protection (measured as loss of body weight after challenge) was comparable to protection observed in the group vaccinated i.m. with the benchmark split-virion vaccine. In contrast, i.n. vaccination with the nonadjuvanted split-virion vaccine-induced only marginal protection, observed in only $20 \%$ of vaccinated animals, which provides direct evidence of the mucosal immunostimulating properties of BLPs. Interestingly, although the observed degree of protection between mice vaccinated i.n. with FluGEM-A and those vaccinated i.m. with split-virion vaccine was similar, the measured lung virus titers differed significantly between these two groups. More specifically, in the lungs of mice vaccinated i.n. with FluGEM-A up to 100fold lower viral load was measured compared to lungs of mice i.m. vaccinated with split-virion vaccine (Figure $\mathbf{3 A}$ ). This is an important observation, as it suggests that i.n. vaccination with FluGEM-A might reduce the shedding of the virus by infected individuals, and thus control the infection at the population level.

The protection level of an i.n. FluGEM-A vaccine against infection with a heterologous influenza virus was also tested (12). For that purpose, mice vaccinated three times i.n. with FluGEM-A containing influenza A/New Caledonia-derived split-virion vaccine were challenged with PR8 virus. The control group was i.m. vaccinated with a $\mathrm{A} / \mathrm{New}$ Caledonia-derived split-virion vaccine. Complete protection was observed only in mice vaccinated with
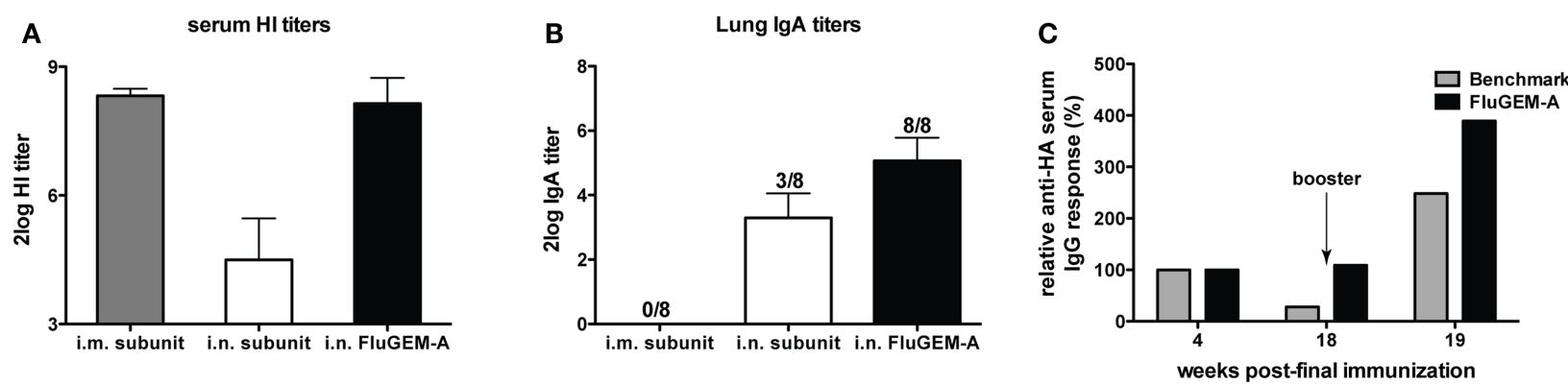

FIGURE 2 | Magnitude and duration of FluGEM-A - induced immune response. Groups of eight mice were vaccinated three times (day 0, 14, and 28) i.n. with FluGEM-A or with benchmark subunit vaccine administered through i.n. or i.m. route. One vaccination dose contained $5 \mu \mathrm{g} \mathrm{HA}$ and in addition to antigen, FluGEM-A vaccine contained $0.3 \mathrm{mg}$ BLPs. HI titers (A) measured in the sera of mice i.n. vaccinated with FluGEM-A were comparable to titers induced upon i.m. vaccination with benchmark subunit vaccine, and higher in comparison to titers induced by i.n. administration with subunit vaccine. S-lgA titers in lung washes (B) were measured in all the mice vaccinated i.n. with FluGEM-A, while only three mice from i.n. subunit group and none of the mice from i.m. subunit group had detectable lung S-IgA titers. Serum IgG titers (C) induced by i.n. vaccination with FluGEM-A remained stable throughout the 18-weeks post-immunization follow-up period and were still boostable. 


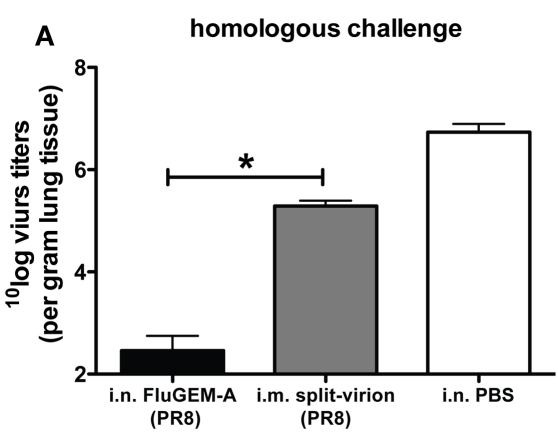

FIGURE 3 | Virus titers measured in the lungs of mice exposed to homologous and heterologous influenza challenge upon i.n. vaccination with FluGEM-A. Groups of six mice were vaccinated three times (day 0, 14 and 28) i.n. with FluGEM-A or i.m. with benchmark split-virion vaccine. Two groups were vaccinated with vaccine derived from PR8 strain (A), and two groups were vaccinated with vaccines derived from New Caledonia strain (B). One vaccination dose contained $5 \mu \mathrm{g} \mathrm{HA}$ and in addition to antigen, FluGEM-A vaccine contained $0.3 \mathrm{mg}$ BLPs. Three weeks after the final immunization (day 49) mice were exposed to challenge with $100 \mathrm{TCID}_{50}$ of

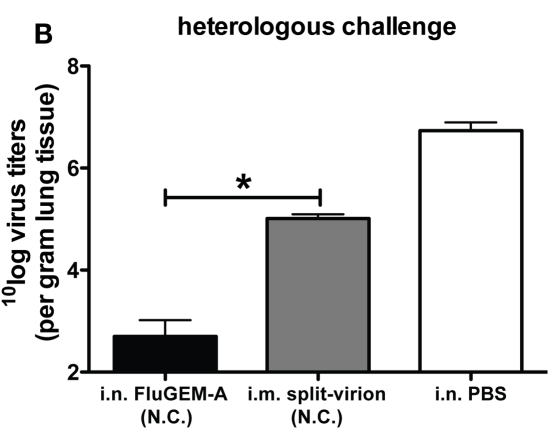

PR8 virus. Lung virus titers were determined 5 days post-challenge. Virus titers measured after homologous challenge in the lungs of mice vaccinated i.n. with PR8-derived FluGEM-A vaccine were up to 100-fold lower compared to titers measured in lungs of mice vaccinated i.m. with PR8-derived split-virion vaccine (A). Virus titers measured after heterologous challenge in the lungs of mice vaccinated i.m. with New Caledonia-derived split-virion vaccine were significantly higher than titers measured in the lungs of mice vaccinated i.n. with New Caledonia-derived FluGEM-A vaccine (B). ${ }^{*} p<0.05$; one-tailed Mann-Whitney $U$ test $(n=6)$ i.n. FluGEM-A vaccine, while a partial protection was observed in animals i.m. vaccinated with the split-virion vaccine. This was also reflected in the lung viral load, which was significantly higher in benchmark vaccinated mice (Figure 3B). One possible explanation for the better clearance of the virus upon both homologous and heterologous influenza challenge in mice i.n. vaccinated with FluGEM-A could be the presence of S-IgA antibodies at the mucosal surfaces of vaccinated animals. It has been shown by others that mucosal vaccination against influenza infection induces full protection, which was dependent on the presence and abundance of mucosal S-IgA antibodies $(27,28)$.

Additional mucosal vaccination routes for delivery of FluGEMA were also explored. A good example of successful mucosal vaccination with influenza subunit vaccine mixed with BLPs is vaccination through the intragastric (i.g.) route (13). Intragastric vaccination of mice with three doses of FluGEM-A containing a seasonal influenza subunit vaccine, induced HI titers above the established protective criterion $(>40)$. High serum IgG and local nasal and intestinal S-IgA titers were detectable 3 weeks after the last vaccination. Similarly to i.n. vaccination, i.g. vaccination with FluGEM-A induced a balanced IgG2a/IgG1 response.

These summarized data clearly demonstrate the immunestimulating properties of BLPs and the ability to convert conventional influenza vaccines into effective mucosal vaccines. Importantly, the immune responses elicited by FluGEM-A provide solid protection against both homologous and heterologous influenza infections, and this protection seems to be superior to the protection observed after i.m. benchmark vaccination. Finally, mucosal vaccination with FluGEM-A, but not i.m. benchmark vaccination, has the capacity to induce robust local S-IgA responses at viral port of entry, which may contribute to superior lung protection after infection and reduced viral shedding.

Influenza antigen bound to BLPs: FluGEM-B. Another type of BLP-based influenza vaccine is prepared by physical coupling (non-covalent binding) of purified influenza antigen (e.g., HA, $\mathrm{M} 2 \mathrm{e}, \mathrm{NP}$ ) to the surface of BLPs, as described in the Section "Introduction" of this review. The main aim of this approach is to also use the BLP as a carrier that present the antigens in a biologically active manner to the immune system. To this end, trimeric HA influenza proteins with a Protan tag were produced in mammalian cell expression systems. The HA-Protan fusion protein is able to form trimers because of the presence of a synthetic multimerization domain that replaces the native HA transmembrane and cytoplasmic domains. The correctly folded trimeric HA-Protan fusion protein is purified from the production medium and as such bound to the surface of BLP (FluGEM-B). FluGEM-B with trimeric $\mathrm{HA}$ is biologically active as demonstrated by its ability to agglutinate red blood cells to a high extent (Figure 4A), in contrast to its monomeric counterpart bound to BLPs, which does not display any hemagglutination properties (Figure 4B).

There are a few potential advantages of the FluGEM-B concept over FluGEM-A. An important safety aspect is that the process of FluGEM-B preparation allows for simple purification of the recombinant HA protein from the host cells and does not require material originating from (inactivated) viruses, which is required for the preparation of FluGEM-A. Furthermore, the FluGEM-B concept allows for inclusion of purified influenza (and noninfluenza) antigens other than HA. This would be particularly beneficial for preparation of multivalent vaccines, e.g., influenza pandemic vaccine based on combination of HA and more conserved proteins (M2e, NP). Finally, it has been shown that physical coupling of soluble (recombinant) antigens to an adjuvant enhances vaccine immunogenicity, by allowing the antigen to be delivered to the same cell activated by the adjuvant $(29,30)$.

To probe the difference between FluGEM-A and FluGEM-B regarding immunogenicity, we vaccinated mice i.n. with both vaccine formulations, using influenza $\mathrm{HA}$ and M2e as antigens. Control groups were i.n. vaccinated with the antigen only. Figure 5 depicts the results of the studies expressed as vaccine-induced 


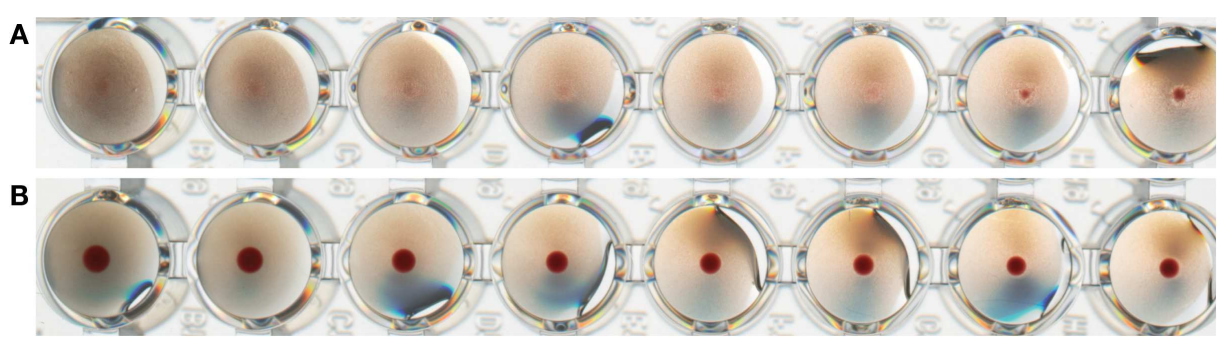

FIGURE 4 | Biological activity of trimeric and monomeric HA-Protan fusion protein bound to BLPs (FluGEM-B) expressed as hemaggluti nation capacity (HAU). Trimeric HA bound to BLPs displays a high capacity to agglutinate turkey red blood cells (A), while monomeric HA bound to BLPs displays no hemagglutination property (B). This suggests that trimeric HA bound to BLPs is properly folded and in biologically active conformation.

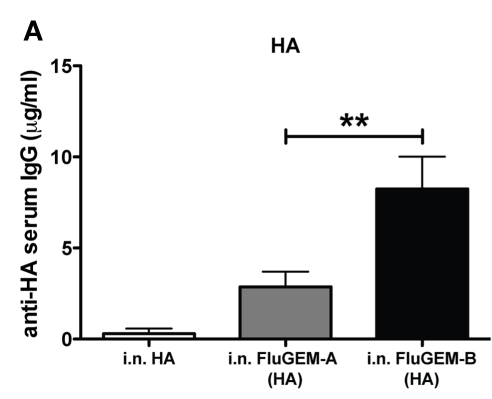

FIGURE 5 | Immune responses induced upon i.n. vaccination with FluGEM-A and FluGEM-B. Groups of 10 mice were vaccinated i.n. with HA- or M2e-based FluGEM-A or FluGEM-B. Vaccination dose in the case of HA-based vaccines (A) was $1 \mu \mathrm{g} \mathrm{HA}$ mixed with or bound to $0.3 \mathrm{mg}$ BLP. Animals received in total three doses (day 0, 10, and 20) and were sacrificed 2 weeks after the final immunization (day 34). Vaccination dose in the case of $\mathrm{M} 2 \mathrm{e}$-based vaccines (B) was $6 \mu \mathrm{g} \mathrm{M} 2 \mathrm{e}$ equivalent mixed with or bound to $0.38 \mathrm{mg}$ BLPS. Animals received in total three doses (day 0,21 , and 42) and were sacrificed 3 weeks after the final immunization (day 63). In both cases physical coupling of the antigen influenza HA- (Figure 5A) or M2e-specific (Figure 5B) serum IgG antibody titers. In both studies, only vaccination with FluGEM$B$ formulations induced seroconversion in all the animals, while vaccination with antigen (HA or M2e) alone induced low serum IgG titers in only a few mice. Moreover, physical coupling of BLP with the antigens contributed to further, approximately fourfold, increase in IgG titers. Additionally, i.n. vaccination with M2ebased (Figure 5C) and HA-based (to be published elsewhere) FluGEM-B induced protection against virus challenge in vaccinated mice, as demonstrated by the decrease in lung viral load in infected vaccinated animals.

Binding of antigen to BLPs presents the further refinement of BLP-based vaccines, as it allows for easier preparation of highly purified proteins with well-preserved biological activity. This concept might also be beneficial for the preparation of multivalent vaccines, as it allows for simple incorporation of different viral antigens in the same vaccine formulation. Finally, it corroborates the assumption that subunit antigens require physical interaction with the adjuvant for optimal vaccine immunogenicity, as illustrated by the examples of HA- and M2e-based vaccines.

\section{Respiratory syncytial virus vaccine: BLP-RSV F (SynGEM)}

Respiratory syncytial virus represents a very important target for development of successful vaccine candidates, as it is the single most important cause of viral bronchiolitis in infants and young children and it is the world-wide leading cause of infant hospitalization (31). Furthermore, elderly and immune-compromised individuals are also at high risk of developing severe RSV disease $(32,33)$. Currently, there is no vaccine available and the only commercially available prophylactic treatment is based on the neutralizing antibody Palivizumab $(34,35)$. Although there is a clear unmet medical need, the development of a safe RSV vaccine has been hampered for decades by the fiasco of the first RSV vaccine developed, Formalin-inactivated RSV (FI-RSV) which induced exacerbation of disease symptoms in a high percentage of vaccinated children and increased the rate of hospitalizations among vaccinees, including some fatalities (36).

With respect to a candidate RSV vaccine, we are developing an intranasal formulation, SynGEM, that is based on the RSV fusion protein (RSV F) bound to BLPs. The choice of antigen was based on the finding that RSV F protein is highly conserved throughout different virus isolates (37) and the only available 
neutralizing antibody Palivizumab is directed against this antigen. The F antigen in SynGEM was produced as a functional trimeric prefusion $\mathrm{F}$ protein in a similar way as trimeric HA was produced. The immunogenicity of SynGEM has been tested in a mouse and cotton rat model. Interestingly, results of both mouse and cotton rat immunization studies with SynGEM were well in line with immunogenicity results obtained from immunizations of mice with FluGEM (11). More specifically, i.n. vaccination with SynGEM induced robust systemic IgG and local S-IgA titers, with a balanced IgG2a/IgG1 ratio. In contrast, i.m. vaccination with FI-RSV induced no local S-IgA and a very low IgG2a/IgG1 ratio $(<0.1)$, indicating an extremely Th2-polarized response (38). Additionally, unlike i.m. vaccination with FI-RSV, mucosal vaccination with SynGEM induced protective virus neutralizing titers, which represent the accepted correlate of protection against RSV. Finally, i.n. vaccination with SynGEM induced a similarly balanced cytokine profile (IFN- $\gamma /$ IL4 ratio), as observed upon i.n. vaccination with FluGEM (11).

One of the most important criteria for a successful RSV vaccine is safety in the context of absence of induction of enhanced disease symptoms. It has been suggested that increased production of IL4 is responsible for exacerbation of disease symptoms, as manifested by severe eosinophilia, lack of neutralizing antibodies and lack of efficient cellular responses (e.g., cytotoxic T lymphocytes CTLs) $(39,40)$. Therefore, vaccination-induced IL4 levels are used as a predictor of the potential immunopathology. An illustrative example of severely Th2 skewed immune responses induced by vaccination is immunization with alum-adjuvanted FI-RSV (41). In contrast, i.n. vaccination with SynGEM induces very low levels of IL4 and the cytokine profile is dominated by production of IFN- $\gamma$, results that are clearly in line with those obtained with i.n. FluGEM vaccination. Additionally, as expected based on the cytokine profile, histopathological analyses in cotton rats indicated that i.n. vaccination with SynGEM does not induce symptoms of enhanced disease (38).

In summary, intranasal vaccination with SynGEM vaccine that is based on trimeric RSV prefusion $F$ protein bound to BLPs, induces robust, well-balanced systemic and local humoral responses. The induced responses were shown to be protective against RSV infection, without inducing enhanced disease symptoms. Therefore, SynGEM represents a promising and safe RSV vaccine candidate.

\section{MODE OF ACTION OF BLPS \\ ACTIVATION OF INNATE IMMUNE SYSTEM}

In Section "Immunogenicity of BLP-Based Vaccines: In vivo Studies" of this overview, examples of different vaccine formulations (FluGEM-A, FluGEM-B, SynGEM) were shown, in which mucosal BLP-based vaccines induce robust, long lasting adaptive immune responses. Successful activation of specific adaptive immune responses relies on optimal activation of innate immune responses, which controls and determines the development of specific adaptive response $(42,43)$. Dendritic cells (DCs) play a crucial role in this process, by being the direct link between the innate and adaptive responses (44). Activation of DCs typically results in cytokine and chemokine production, which further on determine the nature of cellular and humoral responses (45). Finally, only mature and activated DCs have the capacity to (cross-) present the target antigen to CD4+ and CD8+ T-cells (46). The capacity of BLPs to stimulate the innate immunity was well demonstrated in the study of Ramirez et al. (15). In vitro stimulation of murine and human neonatal and adult DCs with BLPs induced maturation of these cells, as illustrated by the increase in expression of surface maturation markers (CD40, CD80, CD86, and MHC class I for murine DCs; CD80, CD83, CD86, and HLA-DR for human DCs). These results are summarized in Table 2. Upon acquisition of a mature phenotype, DCs become capable of antigen (cross-) presentation, which activates the cellular arm of the adaptive immune response. In line with this dogma is the observation that DCs stimulated with BLPs display reduced capacity for antigen uptake, which indicates that these cells became effective antigen-presenters (15).

In addition to the induction of a mature phenotype, BLPs stimulated these DCs to produce proinflammatory, Th1-promoting and regulatory cytokines. Cytokines such as IL-12p70, TNF- $\alpha$, IL-10, IL-6, and IFN- $\gamma$ were secreted by DCs as a response to stimulation with BLPs (Table 2).

Importantly, DCs that have acquired a mature and activated phenotype, as a consequence of stimulation by BLPs, are capable of presenting a specific antigen to target CD4+ and CD8+ T-cells (15). In the study of Ramirez et al. the Y. pestis LcrV model antigen, was bound to BLPs (BLP-LcrV) and used for in vitro activation of specific CD4+ and CD8+ T-cells. DCs stimulated with such a BLP-associated antigen successfully (cross-) presented the antigen to target cells, as illustrated by remarkable proliferation and production of IFN $\gamma$. Additionally, intranasal immunization with BLP-LcrV induced strong activation of antigen-specific antibody secreting cells in the NALT, bone marrow and spleen. The latter organs are considered to be reservoirs of vaccine-induced plasma cells that support production and maintenance of circulating antibodies.

Together, these findings imply that the immunostimulating properties of BLPs rely mainly on the capacity to activate innate immune responses, or more specifically DCs, which are the crucial link between innate and specific adaptive responses. The capacity to induce maturation and activation of antigen-presenting cells (APCs) makes BLPs suitable for delivery of the associated antigen for presentation in the context of MHC class I and/or MHC class II.

\section{INVOLVEMENT OF TLR2}

As demonstrated, the basis for successful induction of robust adaptive immune responses by BLP-based vaccines is activation of innate immune pathways. This is mainly mediated by non-specific recognition of invading pathogens, pathogen-derived components, or microbial-derived components in general. More specifically, the innate immune response is activated by recognition of common microbial associated molecular patterns (MAMPs) by a family of innate immune receptors, such as family of Toll-like receptors (TLRs) (47-49). As a result of recognition of MAMPs by TLRs, an activated state of the innate immune cells is induced. Activated innate immune cells are capable of shaping the adaptive B- and T-cell-mediated responses, depending on the information extracted from the activation signal (49). 
Table 2 | BLP-induced maturation and activation of mouse and human DCs.

\begin{tabular}{|c|c|c|c|c|c|c|c|c|}
\hline & \multicolumn{4}{|c|}{ BLP } & \multicolumn{4}{|c|}{ LPS $^{m}$ orTNF $\alpha^{h}$} \\
\hline & \multicolumn{2}{|c|}{ Neonatal } & \multicolumn{2}{|c|}{ Adult } & \multicolumn{2}{|c|}{ Neonatal } & \multicolumn{2}{|c|}{ Adult } \\
\hline \multicolumn{9}{|c|}{ BLPS INDUCE MATURATION AND ACTIVATION OF MOUSE AND HUMAN DCs } \\
\hline \multicolumn{9}{|c|}{ Markers (fold increase relative to non-stimulated control) } \\
\hline CD80 & 1.2 & 2.2 & 1.1 & 2.5 & 1.4 & 2.7 & 1.8 & 1.8 \\
\hline CD86 & 4.0 & 5.1 & 7.2 & 6.9 & 4.2 & 4.8 & 6.1 & 5.1 \\
\hline I-Ad ${ }^{m}$ or HLA-DR & 1.1 & 1.4 & 8.9 & 3.1 & 0.9 & 1.4 & 7.2 & 3.2 \\
\hline \multicolumn{9}{|c|}{ Cytokines (fold increase relative to non-stimulated control) } \\
\hline IL-12p70 & 1.7 & 2.3 & 1.7 & 1.6 & 2.1 & 1.5 & 1.6 & 2.0 \\
\hline TNF $\alpha$ & 140.1 & 163.0 & 9.4 & 541.8 & 93.4 & 24.4 & 10.8 & 1119.7 \\
\hline MCP1 ${ }^{\mathrm{m}}$ or IL $8^{\mathrm{h}}$ & 1.4 & 58.9 & 1.7 & 13.4 & 2.9 & 125.5 & 1.7 & 2.6 \\
\hline
\end{tabular}

Maturation and activation of neonatal and adult DCs were evaluated by measuring the upregulation of surface markers and production of specific cytokines. ${ }^{m}$, mouse; h, human.

Toll-like receptors are expressed on the surface or in the endosomal compartment of innate immune cells, DCs in particular, and their engagement typically induces cytokine and chemokine production, activation of DCs and subsequent priming of adaptive immune response (50-52). Examples of TLR ligands are: lipopeptides and peptidoglycan (TLR2), viral dsRNA (TLR3), LPS (TLR4), flagelin (TLR5), viral ssRNA (TLR7), bacterial, or CpG DNA (TLR9). Activation of TLRs initiates a signaling cascade directed through the MyD88 and/or TRIF signaling adapters, which in turn activates various transcription factors (49). Due to their innate immune-stimulating properties, TLR ligands have been explored as promising new-generation adjuvants.

An advantage of this new generation of vaccine adjuvants is that their mode of action is well-understood and characterized. The first TLR ligand explored as an adjuvant in a registered vaccine formulation is the TLR4 ligand MPLA used in GSK's HBV vaccine Fendrix ${ }^{\circledR}$ and HPV vaccine Cervarix ${ }^{\circledR}$. Moreover, it has been shown that injection of healthy human subjects with CpG 7909 induces systemic innate immune activation manifested by expression of Th1-polarizing cytokines and IFN-inducible chemokines (53).

Bacterium-like particles belong to this group of new-generation immunostimulators, as its mode of action is well-defined and is based on activation of innate receptor - TLR2, which is a membrane surface receptor, specific for numerous bacterial, fungal, and viral components. Some of the ligands for TLR2 include: Zymosan (S. cerevisiae) (54), LPG (L. major) (55), LPP (56), and HSV (57). Recognition of TLR2 ligand by the receptor initiates the internalization of bound molecules by the endosome/phagosome system and leads to cellular activation. Consequently, cells of the innate immune system, e.g., DCs and macrophages, acquire functions of non-specific immune defense. The most important cytokines participating in this process of activation are TNF- $\alpha$, IL- $1 \alpha$, IL- $1 \beta$,
IL-6, IL-8, and IL-12. TLR2 is expressed on a broad spectrum of different cells, such as monocytes, macrophages, DCs, microglia, polymorphonuclear leukocytes, and B- and T- cells. It is also expressed on the surface of airway epithelia, pulmonary alveoli, and skin keratinocytes (58-61). Very often, TLR2 functions in the form of a heterodimer, when it is associated with TLR1 or TLR6 (62).

The evidence that BLPs activate TLR2 was obtained from both in vitro (using TLR2-specific cell assays) and in vivo studies (immunization studies on TLR2-/- mice). For the in vitro studies, HEK293T cells expressing human TLR2, 3, 4, 5, 7, 8, and 9 and mouse TLR7 and 9, were stimulated with BLPs. The results showed that only the cell line expressing TLR2 responded to BLP stimulation. This observation was corroborated by the fact that the human DCs incubated with an anti-TLR2 antibodies showed a significant decrease in IL-6 production upon incubation with BLPs. These findings suggest that BLPs shape the immune response by activating TLR2 on innate immune cells, e.g., DCs (15). The precise mechanism of the TLR2 activation by BLPs is not completely understood and remains to be elucidated.

In addition to the indirect activation of adaptive responses through the interaction with DCs, recent literature suggests that TLR2 agonists also have a direct effect on the adaptive immune system by interacting with TLR2 expressed on the surface of T-cells (63). One of the consequences of this direct stimulation is induction of Th1-polarized effector responses (63). Furthermore, it has been shown that TLR2 ligands can interact directly with TLR2 on the surface of B-cells. Consequently, the MyD88 signaling cascade within B-cells is initiated, which can trigger IFN $\gamma$ production by T-cells and T-cell dependent IgG2c/a antibody switch (64). Therefore, BLPs possibly have an additional mode of action by inducing Th1-polarized immune responses through direct interaction with TLR2 present on T- and B-cells. 
In addition to the described in vitro studies, intranasal immunizations of wild type ( $w t)$ and TLR2 knockout mice (TLR2-/-) were performed to determine the in vivo effects of the absence of TLR2. This study confirmed that nasal vaccination of mice with influenza split-virion vaccine mixed with BLPs (FluGEM-A) induces local and systemic T- and B-cell responses in a TLR2dependent manner (Keijzer, personal communication). More specifically, upon vaccination with FluGEM-A vaccine the number of IFN $\gamma$-producing cells in the local draining lymph nodes and spleen was significantly reduced in TLR2-/- mice compared to $w t$ mice. Interestingly, absence of TLR2 in knockout mice only moderately effected the IgG levels after vaccination. However, the results of the study showed that class switch toward IgG2c antibody was closely dependent on the interaction of BLP with TLR2, while the levels of IgG1 were very similar between the groups. In line with the previously mentioned study (64), the lack of antibody switch toward IgG2c is closely related to and can be explained by the substantial decrease in IFN $\gamma$ production in TLR2 $-/-$ mice, as this cytokine plays a major role in potentiating IgG2a/c antibody isotype switch. Finally, lack of TLR2 signaling had a negative impact on the development of local mucosal responses, as S-IgA titers measured in nasal and vaginal lavages of TLR2-/ - mice vaccinated with FluGEM-A were largely absent (Table 3 ).

The summarized results provide evidence that the mucosal immunostimulating activity of BLPs, in terms of robust activation of both systemic and local immune responses, depends critically on activation through (innate) TLR2 activation by BLPs.

\section{SAFETY AND IMMUNOGENICITY OF BLP-BASED VACCINES IN HUMANS: FluGEM-A PHASE I CLINICAL TRIAL}

The safety, tolerability, reactogenicity (primary end-point), and immunogenicity (secondary end-point) of intranasal FluGEM-A vaccine composed of seasonal trivalent inactivated influenza vaccine (TIV, season 2009-2010) mixed with BLPs, was evaluated in a randomized, double-blind, controlled phase I clinical trial in male and female subjects aged between 18 and 49 years of age. As a parallel control vaccine, i.n. administered non-adjuvanted TIV antigen was used. Details of the study are prepared for publication elsewhere. Primary safety end-points for FluGEMA were not distinguishable from those of plain unadjuvanted TIV with respect to severity, duration, and number of adverse events (AEs). No severe AEs were reported. Moreover, there was no evidence of increased frequency of complaints after the second administration, suggesting no cumulative effect of vaccination with intranasal BLP-based vaccine. Based on the data summarized above, we conclude that intranasal FluGEM-A vaccine tested in human adults is safe and well tolerated as far as can be determined in a limited number of study subjects. As an exploratory safety parameter the anti-lactococcal serum antibody response before and after complete vaccination was measured in order to determine the suitability of repeated use of BLP-based vaccines in humans. In addition, we summarize below results of primary and exploratory immunology analyses, obtained for the FluGEMA group vaccinated with $1.25 \mathrm{mg}$ BLPs mixed with a standard TIV antigen dose of $15 \mu \mathrm{g}$ HA per strain and the TIV antigen only group with the same standard HA dose per strain as the FluGEM-A group. The two study groups consisted of 15 subjects each. The vaccine dose was administered in a volume of $250 \mu \mathrm{l}$, equally divided between two nostrils. Seasonal TIV was composed of the following viral strains: A/California/7/2009 (H1N1), A/Perth/16/2009 (H3N2), and B/Brisbane/60/2008. The subjects received on day 0 and 21 a single intranasal dose of FluGEM-A or TIV alone and were followed for 210 days post-vaccination. The primary analysis of systemic immunogenicity was through systemic HI titers against each of the included viral strains and mucosal (nasal) influenza-specific S-IgA antibody levels. In addition, for exploratory purposes, antigen-specific IFN $\gamma$-producing cells were enumerated among peripheral blood mononuclear cells (PBMCs) collected on days $0,7,21$, and 28 post-prime vaccination.

\section{FluGEM-A VACCINE IS SUITABLE FOR REPEATED VACCINATION: RESPONSE AGAINST THE BLP CARRIER}

Another important aspect of BLP-based vaccines is whether antibodies against the L. lactis-derived immune-stimulating component, are induced. These may possibly hamper (repeated) vaccination with BLP-based vaccines. For this purpose, the status of L. lactis-specific antibodies prior- and post-vaccination was determined.

In all the subjects, serum antibody titers against L. lactis proteins were measured before the start of the vaccination (day 0 ) and 3 weeks after the second vaccination (day 42). Pre-vaccination levels of L. lactis-specific antibodies in all the subjects were high (in the FluGEM-A group the mean pre-vaccination titer was $1.3 \times 10^{4}$, with $\max =4.2 \times 10^{4}$ and $\min =2.3 \times 10^{3}$; in the TIVonly group the mean pre-vaccination titer was $1.3 \times 10^{4}$, with $\max =5.1 \times 10^{4}$ and $\left.\min =0.8 \times 10^{3}\right)$. Figure 6 represents the relative change in $L$. lactis-specific antibody titers 3 weeks after the final vaccination showing that vaccination with FluGEM-A did not increase the level of L. lactis-specific antibodies. In both vaccination groups no changes in antibody titers were measured. Thus, the results indicate that BLPs do not enhance the levels of

Table 3 | Immunostimulatory capacity of BLPs in vivo critically depends on TLR2 activation.

\begin{tabular}{|c|c|c|c|c|c|c|c|c|c|}
\hline \multirow{2}{*}{$\begin{array}{l}\text { Mouse } \\
\text { type }\end{array}$} & \multicolumn{2}{|c|}{$\begin{array}{l}\text { IFN } \gamma \text {-producing cells } \\
\text { (per } 10^{6} \text { cells) }\end{array}$} & \multicolumn{2}{|c|}{$\begin{array}{l}\text { IAV-specific B-cells } \\
\text { (per } 10^{6} \text { cells) }\end{array}$} & \multirow{2}{*}{$\begin{array}{l}\text { Serum IgG } \\
(\mu \mathrm{g} / \mathrm{ml})\end{array}$} & \multirow{2}{*}{$\begin{array}{l}\text { Serum lgG2c } \\
(\mu \mathrm{g} / \mathrm{ml})\end{array}$} & \multirow{2}{*}{$\begin{array}{l}\text { Serum lgG1 } \\
(\mu \mathrm{g} / \mathrm{ml})\end{array}$} & \multicolumn{2}{|c|}{ S-lgA titer } \\
\hline & LN & Spleen & LN & Spleen & & & & Nasal lavage & Vaginal lavage \\
\hline \multicolumn{10}{|c|}{ BLP-INDUCED IMMUNE RESPONSE CRITICALLY DEPENDS ONTLR2 ACTIVATION } \\
\hline TLR2-/- & 30 & 102 & 3 & 4 & 10.5 & 1.0 & 8.0 & - & 0.5 \\
\hline$w t$ & 98 & 2701 & 10 & 8 & 24.4 & 6.3 & 4.9 & 2.5 & 7.1 \\
\hline
\end{tabular}


L. lactis-specific antibodies, which suggests FluGEM-A and other BLP-based vaccines are suitable for repeated administration.

\section{IMMUNOGENICITY OF INTRANASALLY DELIVERED FluGEM-A VACCINE}

The primary measured immunological parameters were serum $\mathrm{HI}$ titers and mucosal (nasal) influenza-specific S-IgA against each of the viral strains included in the vaccine. Additionally, in order to characterize cellular immune responses upon vaccination, PBMCs were tested for presence of IFN $\gamma$-secreting cells.

\section{Hemagglutination inhibition titers}

Serum HI titers represent the generally accepted surrogate marker for evaluation of efficacy of influenza vaccines and vaccination protocols. Table 4 summarizes results of HI geometric mean titers (GMTs) and GMT ratios measured in all the study subjects on day $0,21,42$, and 210, regardless of their baseline $\mathrm{HI}$ titers, against all the influenza strains included in the vaccine.

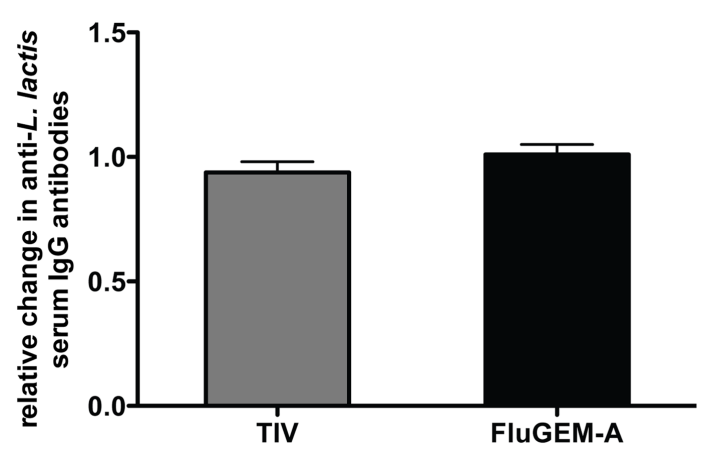

FIGURE 6 | Relative change in BLP-specific antibody titer after i.n. vaccination with FluGEM-A. Blood samples were collected from all test subjects and $L$. lactis-specific antibody titers were determined on study days 0 (baseline titers) and 42. In both vaccination groups (i.m. TIV and i.n. FluGEM-A) no increase in L. lactis-specific antibody titers due to vaccination were measured.
A clear increase in HI titers against all strains present in the vaccine was already observed after one i.n. administration with FluGEM-A. No additional increase in titers was observed after administration of the second vaccine dose. Although the titers observed after FluGEM-A administration were higher for all strains at each time-point, the HI levels obtained after administration with TIV-only were already surprisingly high. As shown in Table 4, i.n. vaccination with FluGEM-A induced GMT ratios $>2.5$, which were at least twice as high as the ratios recorded in TIV-only group. Importantly, HI GMT titers $\geq 40$ were achieved in subjects i.n. vaccinated with FluGEM-A after administration of only one vaccine dose. The titers against all three strains remained stable throughout the whole follow-up period of almost 6 months, which is in line with previously presented results of duration of immunity induced by vaccination of mice with FluGEM-A.

Intranasal FluGEM-A vaccine fulfilled the EMA criteria for a seasonal influenza vaccine, i.e., at least one criteria out of the following was met: seroconversion in $>40 \%$ of subjects, seroprotection (HI titers $\geq 40$ ) in $>70 \%$ of subjects, and mean geometric increase in titer $>2.5$, for each influenza strain included in the vaccine.

To describe the dynamics in HI titers more accurately, in Figure 7 we depict the change in HI titers for all three influenza strains after vaccination, measured in subjects with $\mathrm{HI}$ baseline titers $<10$. For all three influenza strains, in particular B and H3N2, vaccination with FluGEM-A induced higher-magnitude responses, when compared to responses induced by i.n. vaccination with TIV-only vaccine. Additionally, GMTs induced upon i.n. vaccination with control TIV vaccine did not (strain B) or barely (strain $\mathrm{H} 1 \mathrm{~N} 1$ ) reach the protective threshold titer of 40 .

\section{Influenza-specific mucosal (nasal) IgA response}

To evaluate the capacity of FluGEM-A to induce local mucosal responses, influenza-specific S-IgA titers in nasal washes of vaccinated subjects were measured. Figure 8 summarizes the titers of

Table 4 | HI titers specific for all three influenza strains included in the vaccine.

\begin{tabular}{|c|c|c|c|c|c|c|c|c|}
\hline Vaccination group & \multicolumn{4}{|l|}{ TIV } & \multicolumn{4}{|c|}{ FluGEM-A } \\
\hline \multicolumn{9}{|c|}{ HI GEOMETRIC MEAN TITERS AND RATIO TO BASELINE TITERS } \\
\hline Study day & 0 & 21 & 42 & 210 & 0 & 21 & 42 & 210 \\
\hline Number of subjects & 13 & 13 & 13 & 13 & 10 & 10 & 10 & 10 \\
\hline HI GMT & 10.5 & 29.9 & 32.4 & 50.6 & 8.5 & 48.1 & 47.8 & 63.9 \\
\hline Number of subjects & 11 & 11 & 11 & 11 & 11 & 11 & 11 & 11 \\
\hline HI GMT & 10.4 & 49.5 & 53.8 & 40.8 & 23.2 & 118.0 & 109.9 & 131.7 \\
\hline HI GMT ratio & 1.0 & 4.8 & 5.2 & 3.9 & 1.0 & 5.1 & 4.7 & 5.7 \\
\hline \multicolumn{9}{|c|}{ Influenza H3N2 strain } \\
\hline Number of subjects & 15 & 15 & 15 & 15 & 12 & 12 & 12 & 12 \\
\hline
\end{tabular}

HI titers were measured on study days 0 (baseline) 21, 42, and 210. 


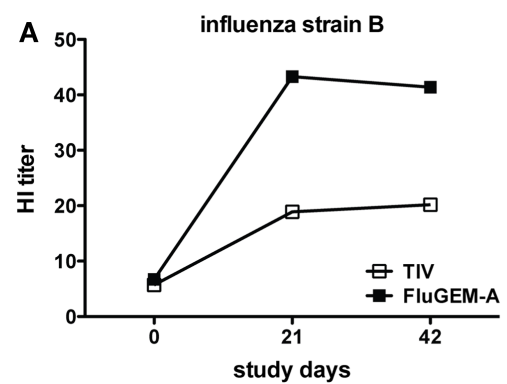

FIGURE 7 | Change in $\mathrm{HI}$ titers against (A) influenza $B$, (B) influenza H1N1 (C) and influenza H3N2 upon vaccination. HI titers in sera of study subjects were measured on study days 0 (baseline titers), 21, and 42. Only titers measured in subjects with baseline $<40$ are depicted. For
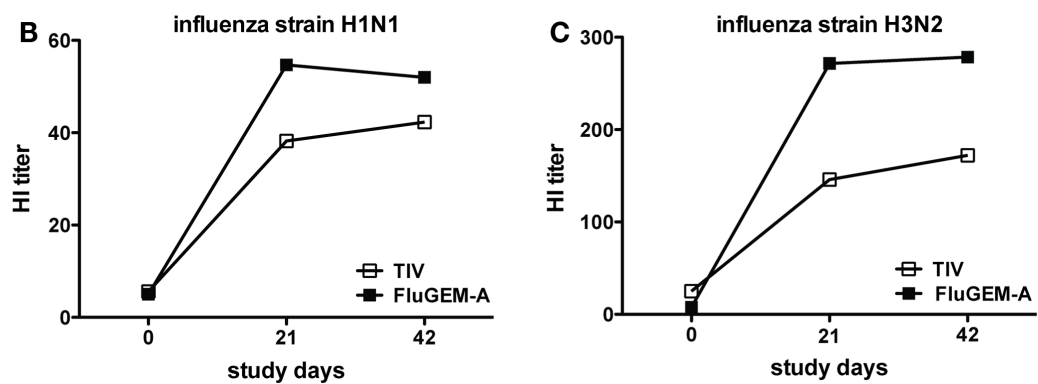

all three influenza strains, responses induced by i.n. vaccination with FluGEM-A were faster and of higher-magnitude, when compared to responses induced by i.n. vaccination with TIV (barely reach protective titer of 40 )

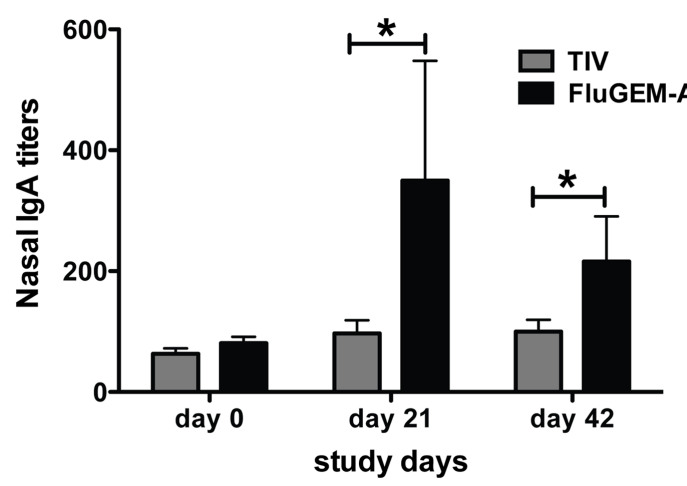

FIGURE 8 | Influenza-specific IgA titers measured in nasal lavages of vaccinated subjects. Nasal lavages of study subjects were collected and IgA titers assessed on study days 0 (baseline), 21, and 42. On both days 21 and 42 titers measured in nasal lavages of subjects vaccinated i.n. with FluGEM-A were significantly higher than titers measured in lavages of subjects vaccinated i.n. with TIV. Increase in nasal IgA titers in FluGEM-A vaccination group relative to the baseline was approximately $100 \%$ by day 21. ${ }^{*} p<0.05$; one-tailed Mann-Whitney $U$ test.

the nasal influenza-specific S-IgA antibodies. Only subjects with $\mathrm{S}$-IgA values available at all the time points are included in the table.

An increase of approximately fourfold relative to the baseline titers was recorded in the FluGEM-A group already on day 21 . This was associated with a high seroconversion rate of approximately $70 \%$. In contrast, only a minor increase in influenza-specific SIgA levels was detected in nasal washes of some of the participants in the control TIV group after vaccination. Thus, i.n. vaccination with FluGEM-A induces, in addition to systemic response (HI titers), a robust nasal S-IgA response.

\section{Cellular (IFNy) response}

IFN $\gamma$ is a cytokine whose immunostimulatory and immunomodulatory functions are critical for both innate and adaptive immune responses. To evaluate the IFN $\gamma$ responses induced by vaccination with FluGEM-A, PBMCs were collected from vaccinated subjects on days $0,7,21$, and 28 and the number of IFN $\gamma$-producing cells were enumerated after restimulation with TIV. Figure 9 represents the vaccination-induced increase in number of IFN $\gamma$-producing cells, specific for H1N1 (Figure 9A) and H3N2 (Figure 9B) influenza strains. Results are presented as a mean increase from baseline (number of specific cells measured on day 0 per $10^{6}$ cells) with $95 \%$ confidence intervals depicted. Presented results show a trend of increase in the number of specific IFN $\gamma$-producing cells from day 0 to day 21 among PBMCs isolated from subjects vaccinated i.n. with FluGEM-A and the increase became significant for both strains after the booster immunization. This trend and significant increase at day 28 is not observed in PBMCs isolated from subjects vaccinated i.n. with TIV and a plateau in the number of IFN $\gamma$ producing PBMCs in this vaccination group is reached 1 week after the primary vaccination.

We conclude that i.n. vaccination with FluGEM-A, in addition to activation of humoral immune response, and unlike i.n. vaccination with TIV, stimulates cellular responses in human subjects, as shown by a vaccine-induced increase in the number of influenza-specific IFN $\gamma$-producing PBMCs.

\section{FINAL REMARIKS}

Mucosal vaccines offer several advantages, as demonstrated by the described BLP-based vaccines, in comparison to the current, classical, injectable vaccines. Besides the ease of needle-free administration, mucosal vaccines are capable of inducing both systemic and local responses at the surface of mucosae. In this way, these vaccines already provide a first line of defense in the form of S-IgA at the port of entry of most pathogens. Additionally, locally produced S-IgA antibodies have been suggested to be less sensitive to antigenic variation (28) and may therefore provide broader protection. Our observations with FluGEM-A in heterologous challenge studies seem to be in line with this hypothesis (12).

The limited immunogenicity data derived from the Phase I clinical trial appears to confirm the promising preclinical data. Subjects that received FluGEM-A via the i.n. route showed systemic HI titers and local S-IgA responses. Induction of humoral responses was associated with the production of the immunomodulatory cytokine, IFN $\gamma$. Whether the local and systemic responses induced in humans by mucosal vaccination with FluGEM-A in particular and BLP-based vaccines in general will result in 
A

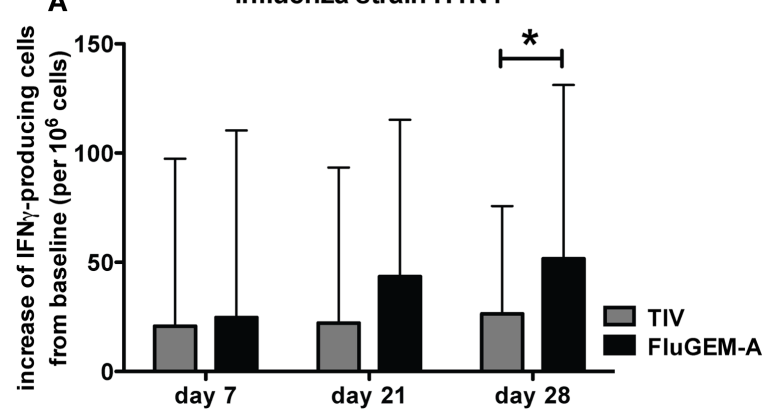

FIGURE 9 | FluGEM-A induced increase in influenza H1N1- (A) and H3N2-specific (B) IFN $\gamma$-producing T-cells. Blood samples were collected from study participants on study days $0,7,21$, and 28 . PBMCs were isolated and IFN $\gamma$-producing cells were enumerated by

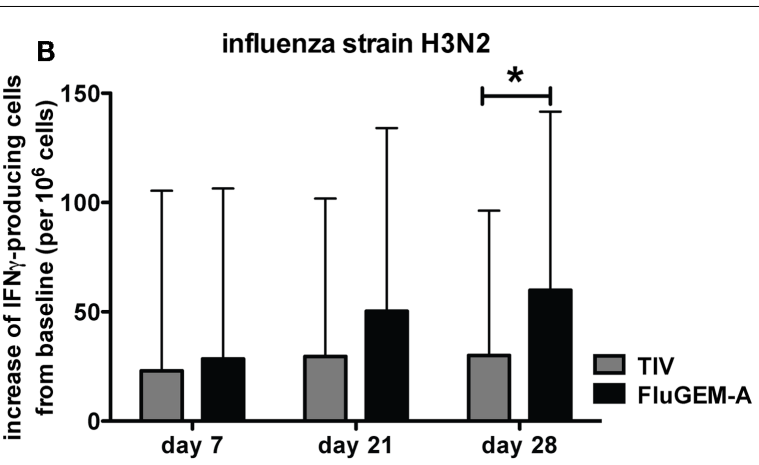

ELISPOT assay. Results are presented as a mean increase from a baseline (number of specific cells measured on day 0 per $10^{6}$ cells) with $95 \%$ confidence interval depicted. ${ }^{*} p<0.05$; two-tailed Student t-test.

example, fuels the required evolution in vaccine design and protection against pathogen infections. Well-understood modes of action of such compounds allows for rational design of safe and protective vaccines with the desired immune responses.

\section{REFERENCES}

1. Moyle PM, Toth I. Modern subunit vaccines: development, components and research opportunities. ChemMedChem (2013) 8:360-76. doi:10.1002/cmdc. 201200487

2. Leroux-Roels G. Unmet needs in modern vaccinology: adjuvants to improve the immune response. Vaccine (2010) 28(Suppl 3): C25-36. doi:10.1016/j.vaccine. 2010.07.021

3. Pashine A, Valiante NM, Ulmer JB. Targeting the innate immune response with improved vaccine adjuvants. Nat Med (2005) 11:S63-8. doi:10.1038/nm1210

4. Silhavy TJ, Kahne D, Walker S. The bacterial cell envelope. Cold Spring Harb Perspect Biol (2010) 5(2):a000414. doi:10.1101/ cshperspect.a000414

5. Hancock IC. Bacterial cell surface carbohydrates: structure and assembly. Biochem Soc Trans (1997) 1:183-7.

6. Bosma T, Kanninga R, Neef J, Audouy SA, van Roosmalen M, Steen A, et al. A novel surface display system for proteins on nongenetically modified Gram-positive bacteria. Appl Environ Microbiol (2006) 72:880-9. doi:10.1128/AEM. 72.1.880-889.2006

7. Buist G, Kok J, Leenhouts KJ, Dabrowska M, Venema G, Haandrikman AJ. Molecular cloning and nucleotide sequence of the gene encoding the major peptidoglycan hydrolase of Lactococcus lactis, a muramidase needed for cell separation. J Bacteriol (1995) 177:1554-63.

8. Roosmalen ML, van Kanninga R, El Khattabi M, Neef J, Audouy $\mathrm{S}$, Bosma $\mathrm{T}$, et al. Mucosal vaccine delivery of antigens tightly bound to an adjuvant particle made from food-grade bacteria. Methods (2006) 38:144-9. doi:10.1016/j. ymeth.2005.09.015

9. Leenhouts K. Mimopath-based vaccine delivery. In: Singh M, editor. Novel Immune Potentiators and Delivery Technologies for Next Generation Vaccines. New York: Springer (2013). p. 245-65.

10. Saluja V, Visser MR, Ter Veer W, Roosmalen ML, van Leenhouts $\mathrm{K}$, Hinrichs WL, et al. Influenza antigen-sparing by immune stimulation with Gram-positive enhancer matrix (GEM) particles. Vaccine (2010) 28:7963-9. doi:10.1016/j. vaccine.2010.09.066

11. Saluja V, Amorij JP, Roosmalen ML, van Leenhouts $\mathrm{K}$, Huckriede A, Hinrichs WL, et al. Intranasal delivery of influenza subunit vaccine formulated with GEM particles as an adjuvant. AAPS J (2010) 12: 109-16. doi:10.1208/s12248-0099168-2

12. de Haan A, Haijema BJ, Voorn $\mathrm{P}$, Meijerhof $\mathrm{T}$, van Roosmalen ML, Leenhouts K. Bacterium-like particles supplemented with inactivated influenza antigen induce cross-protective influenza-specific responses through intranasal administration. Vaccine (2012) 6: 4884-91. doi:10.1016/j.vaccine. 2012.04.032

13. Saluja V, Visser MR, van Roosmalen ML, Leenhouts K, Huckriede A, Hinrichs WL, et al. Gastro-intestinal delivery of influenza subunit vaccine formulation adjuvanted with Gram-positive enhancer matrix (GEM) particles. Eur J Pharm Biopharm (2010) 76:470-4. doi:10.1016/j.ejpb.2010.08.003

14. Audouy SA, Selm S, van Roosmalen ML, van Post E, Kanninga R, Neef J, et al. Development of lactococcal GEM-based pneumococcal vaccines. Vaccine (2007) 25:2497-506. doi:10.1016/j.vaccine. 2006.09.026

15. Ramirez K, Ditamo Y, Rodriguez L, Picking WL, Roosmalen ML, Leenhouts $\mathrm{K}$, et al. Neonatal mucosal immunization with a non-living, non-enetically modified Lactococcus lactis vaccine carrier induces systemic and local Th1-type immunity and protects against lethal bacterial infection. Mucosal Immunol (2010) 3:159-71. doi:10.1038/mi. 2009.131

16. Nganou-Makamdop K, van Roosmalen ML, Audouy SAL, van Gemert G, Leenhouts K, Hermsen CC, et al. Bacterium-like particles as multi-epitope delivery platform for Plasmodium berghei circumsporozoite protein induce complete protection against malaria in mice. Malar J (2012) 11:50. doi:10.1186/ 1475-2875-11-50

17. Fleming DM. The contribution of influenza to combined acute respiratory infections, hospital admissions, and death in winter. Commun Dis Public Health (2000) 3:32-8.

18. Stohr K. Influenza - WHO cares. Lancet Infect Dis (2002) 2:517. doi: 10.1016/S1473-3099(02)00366-3

19. Lamb RA, Choppin PW. The gene structure and replication of influenza virus. Annu Rev Biochem (1983) 52:468-506. doi:10.1146/ annurev.bi.52.070183.002343

20. Lamb RA, Krug RM. Orthomyxoviridae: the viruses and their replication. 4th ed. In: Knipe DM, Griffin DE, editors. Fields Virology. Philadelphia: Lippincott Williams \& Wilkins (2001). p. 1487-531.

21. Artenstein AW. Influenza. In: Artenstein AW, editor. Vaccines: A Biography. New York: Springer (2010). p. 191-205.

22. Cox RJ, Brokstad KA, Ogra P. Influenza virus: immunity and vaccination strategies. Comparison of the immune response to inactivated and live, attenuated influenza vaccines. Scand J Immunol (2004) 59:1-15. doi:10.1111/j.0300-9475. 2004.01382.x

23. Giudice EL, Campbell JD. Needlefree vaccination delivery. Adv Drug Deliv Rev (2006) 58:68-89. doi:10. 1016/j.addr.2005.12.003 
24. Matassov D, Cupo A, Galarza JM. A novel intranasal virus-like particle (VLP) vaccine designed to protect against the pandemic 1918 influenza A virus (H1N1). Viral Immunol (2007) 20:441-52. doi:10. 1089/vim.2007.0027

25. de Haan L, Verweij WR, Holtrop $M$, Brands $R$, van Scharrenburg GJM, Palache AM, et al. Nasal or intramuscular immunization of mice with influenza subunit antigen and the $\mathrm{B}$ subunit of Escherichia coli heat-labile toxin induces IgA- or IgG-mediated protective mucosal immunity. Vaccine (2001) 19:2898-907. doi:10.1016/ S0264-410X(00)00556-9

26. Fujihashi K, Koga T, van Ginkel FW, Hagiwara Y, McGhee JR. A dilemma for mucosal vaccination: efficacy versus toxicity using enterotoxin-based adjuvants. Vaccine (2002) 20:2431-8. doi:10.1016/ S0264-410X(02)00155-X

27. Takada A, Matsushita S, Ninomiva A, Kawaoka Y, Kida H. Intranasal immunization with formalininactivated virus vaccine induces a broad spectrum of heterosubtypic immunity against influenza A virus infection in mice. Vaccine (2003) 21:3212-8. doi:10.1016/S0264410X(03)00234-2

28. Asahi-Ozaki Y, Yoshikawa T, Jwakura Y, Suzuki Y, Tamura S, Kurata T, et al. Secretory IgA antibodies provide cross-portection against infection with different strains of influenza B virus. J Med Virol (2004) 74:328-35. doi:10.1002/jmv.20173

29. Fujita Y, Taguchi H. Overview and outlook of Toll-like receptor ligandantigen conjugate vaccines. Ther Deliv (2012) 3:749-60. doi:10.4155/ tde. 12.52

30. Eckl-Dorna J, Batista FD. BCRmediated uptake of antigen linked to TLR9 ligand stimulates Bcell proliferation and antigenspecific plasma cell formation. Blood (2009) 113:3969-77. doi:10. 1182/blood-2008-10-185421

31. Tregoning JS, Schwarze J. Respiratory viral infections in infants: causes, clinical symptoms, virology and immunology. Clin Microbiol Rev (2010) 23:74-98. doi:10.1128/ CMR.00032-09

32. Falsey AR, Walsh EE. Respiratory syncytial virus infection in adults. Clin Microbiol Rev (2000) 13:371-84. doi:10.1128/CMR.13.3. 371-384.2000

33. Englund JA, Anderson LJ, Rhame FS. Mosocomial transmission of respiratory syncytial virus in immunocompromised. $J \quad C l i n$ Microbiol (1991) 29:115-9.

34. Sun Z, Pan Y, Jiang S, Lu L. Respiratory syncytial virus entry inhibitors targeting F protein. Viruses (2013) 5:211-25. doi:10.3390/v5010211

35. Andabaka T, Nickerson JW, RojasReyes MX, Rueda JD, Bacic Vrca V, Barsic B. Monoclonal antibody for reducing the risk of respiratory syncytial virus infection in children. Cochrane Database Syst Rev (2013) 4:CD006602. doi:10.1002/ 14651858.CD006602.pub4

36. Kim H, Canchola JG, Brandt CD, Pyles G, Chanock RM, Jensen K, et al. Respiratory syncytial virus disease in infants despite prior administration of antigenic inactivated vaccine. Am J Epidemiol (1969) 89:422-34.

37. Tan L, Lemey P, Houspie L, Viveen MC, Jansen NJ, van Loon AM, et al. Genetic variability among complete human respiratory syncytial virus subgroup A genomes: bridging molecular evolutionary dynamics and epidemiology. PLOS ONE (2012) 7(12):e51439. doi:10.1371/ journal.pone.0051439

38. Rigter A, Widjaja I, Versantvoort $\mathrm{H}$, Coenjaerts FEJ, van Roosmalen $\mathrm{M}$, Leenhouts $\mathrm{K}$, et al. A protective and safe intranasal RSV vaccine based on a recombinant prefusionlike form of the $\mathrm{F}$ protein bound to bacterium-like particles. PLoS ONE (2013) 8(8):e71072. doi:10 1371/journal.pone.0071072

39. Graham BS, Henderson GS, Tang YW, Neuzil KM, Colley DG. Priming immunization determines $\mathrm{T}$ helper cytokine mRNA expression patterns in lungs of mice challenged with respiratory syncytial virus. J Immunol (1993) 151:2032-40.

40. Tang YW, Graham BS. Anti-IL-4 treatment at immunization modulates cytokine expression, reduces illness, and increases cytotoxic $\mathrm{T}$ lymphocyte activity in mice challenged with respiratory syncytial virus. J Clin Invest (1994) 94:1953-8. doi:10.1172/JCI117546

41. Connors M, Giese NA, Kulkami $\mathrm{AB}$, Firestone CY, Morse HC 3rd, Murphy BR. Enhanced pulmonary histopathology induced by respiratory syncytial virus (RSV) challenge of formalin-inactivated RSVimmunized $\mathrm{BALB} / \mathrm{C}$ mice is abrogated by depletion of interleukin4 (IL-4) and IL-10. J Virol (1994) 68:5321-5.

42. Iwasaki R, Medzhitov R. Regulation of adaptive immunity by the innate immune system.
Science (2010) 327:291-5. doi:10.1126/science.1183021

43. Schenten D, Medzhitov R. The control of adaptive immune responses by the innate immune system. Adv Immunol (2011) 109:87-124. doi:10.1016/B978-0-12-387664-5. 00003-0

44. Steinman RM, Hemmi H. Dendritic cells: translating innate to adaptive immunity. Curr Top Microbio Immunol (2006) 311:17-58. doi:10. 1007/3-540-32636-7_2

45. Curtsinger JM, Schmidt CS Mondino A, Lins DC, Kedl RM, Jenkins MK, et al. Inflamatory cytokines provide a third signal for activation of naïve $\mathrm{CD} 4+$ and CD8+ T cells. J Immunol (1999) 162:3256-62.

46. Storni T, Lechner F, Erdmann I, Bachi T, Jegerlehner A, Dumrese T, et al. Critical role for activation of antigen-presenting cells in priming of cytotoxic $\mathrm{T}$ cell responses after vaccination with virus-like particles. J Immunol (2002) 168:2880-6.

47. Akira S, Uematsu S, Takeuch O. Pathogen recognition and innate immunity. Cell (2006) 124:783-801. doi:10.1016/j.cell.2006.02.015

48. Medzhitov R, Janeway C Jr Innate immunity. $N$ Engl J Med (2000) 343:338-44. doi:10.1056/ NEJM200008033430506

49. Mogensen TH. Pathogen recognition and inflammatory signaling in innate immune defense. Clin Microbiol Rev (2009) 22:240-73. doi:10. 1128/CMR.00046-08

50. Kumar H, Kawai T, Akira $S$. Pathogen recognition by the innate immune system. Int Rev Immunol (2011) 30:16-34. doi:10.3109/08830185.2010.529976

51. Hajishengallis G, Lambris JD. Microbal manipulation of receptor crosstalk in innate immunity. Nat Rev Immunol (2011) 11:187-200 doi:10.1038/nri2918

52. Jin $B$, Sun $T$, Yu XH, Yang $Y X$ Yeo AE. The effects of TLR activation on T-cell development and differentiation. Clin Dev Immunol (2012) 2012:1-32. doi:10.1155/2012/836485

53. Krieg AM, Efler SM, Wittpot M, A Adhami MJ, Davis HL. Induction of systemic Th1-like innate immunity in normal volunteers following subcutaneous but not intravenous administration of CpG 7909, a synthetic B-class $\mathrm{CpC}$ oligodeoxynucleotide TLR9 agonist. J Immunother (2004) 27:460-71. doi:10.1097/00002371200411000-00006
54. Underhill DM, Ozinsky A, Hajjar AM, Stevens A, Wilson CB, Bassetti $\mathrm{M}$, et al. The Toll-like receptor 2 is recruited to macrophage phagosomes and discriminates between pathogens. Nature (1999) 401:811-5. doi:10.1038/44605

55. Becker I, Salaiza N, Aguirre M, Delgado J, Carrillo-Carrasco N, Kobeh LG, et al. Leishmania lipophosphoglycan (LPG) activates NK cells through toll-like receptor 2. Mol Biochem Parasitol (2003) 31:65-74. doi:10.1016/S01666851(03)00160-9

56. Ostuni R, Zanoni I, Granucci F. Deciphering the complexity of Tolllike receptor signaling. Cell Mol Life Sci (2010) 67:4109-34. doi:10.1007/ s00018-010-0464-x

57. Kim M, Osborne NR, Zeng W, Donaghy H, McKinnon K, Jackson DC, et al. Herpes simplex virus antigens directly activate NK cells via TLR2, thus facilitating their presentation to $\mathrm{CD} 4 \mathrm{~T}$ lymphocytes. J Immunol (2012) 188:4158-70. doi:10.4049/ jimmunol.1103450

58. Kim C, Ho DH, Suk JE, You S, Michael S, Kang J, et al. Neuron-released oligomeric $\alpha$-synclein is an endogenous agonist of TLR2 for paracrine activation of microglia. Nat Commun (2013) 4:1562. doi:10.1038/ncomms 2534

59. Wu Q, Jiang D, Minor MN, Martin RJ, Chu HW. In vivo function of airway epithelial TLR2 in host defense against bacterial infection. Am J Physiol Lung Cell Mol Physiol (2011) 300:L579-86. doi:10.1152/ajplung.00336.2010

60. Droemann D, Goldmann T, Branscheid D, Clark R, Dalhoff K, Zabel $\mathrm{P}$, et al. Toll-like receptor 2 is expressed by alveolar epithelial cells type II and macrophages in the human lung. Histochem Cell Biol (2003) 119:103-8.

61. Bakker BS, Ovigne JM, Powles AV, Corcoran S, Fry L. Normal keratinocytes express Toll-like receptors (TLRs) 1,2 and 5: modulation of TLR expression in chronic plaque psoriasis. $\mathrm{Br} J$ Dermatol (2003) 148:670-9. doi:10.1046/ j.1365-2133.2003.05287.x

62. Farhat K, Riekenberg S, Heine $\mathrm{H}$, Debarry J, Lang R, Mages $\mathrm{J}$, et al. Heterodimerization of TLR2 with TLR1 or TLR6 expands the ligand spectrum but does not lead to differential signaling. $J$ Leukoc Biol (2008) 83:692-701. doi: 10.1189/jlb.0807586 
63. Imanishi $T$, Hara $H$, Suzuki S, Suzuki N, Akira S, Saito T. Cutting edge: TLR2 directly triggers Th1 effector function. J Immunol (2007) 178:6715-9.

64. Barr TA, Brown S, Mastroeni P, Gray D. B cell intrinsic MyD88 signals drive IFN-gamma production from $\mathrm{T}$ cells and control switch to IgG2c. J Immunol (2009) 183:1005-12. doi: 10.4049/jimmunol.0803706
Conflict of Interest Statement: The authors are employees of the organization that funded all the work described in the paper.

Received: 10 June 2013; accepted: 31 August 2013; published online: 17 September 2013.

Citation: Van Braeckel-Budimir N, Haijema BJ and Leenhouts K (2013)
Bacterium-like particles for efficient immune stimulation of existing vaccines and new subunit vaccines in mucosal applications. Front. Immunol. 4:282. doi: 10.3389/fimmu.2013.00282 This article was submitted to Immunotherapies and Vaccines, a section of the journal Frontiers in Immunology. Copyright (c) 2013 Van Braeckel-Budimir, Haijema and Leenhouts. This is an open-access article distributed under the terms of the Creative Commons Attribution License (CC BY). The use, distribution or reproduction in other forums is permitted, provided the original author(s) or licensor are credited and that the original publication in this journal is cited, in accordance with accepted academic practice. No use, distribution or reproduction is permitted which does not comply with these terms. 